\title{
Efficacy and safety of twice-daily glycopyrrolate in patients with stable, symptomatic COPD with moderate-to-severe airflow limitation: the GEMI study
}

\author{
This article was published in the following Dove Press journal: \\ International Journal of COPD \\ 8 June 2016 \\ Number of times this article has been viewed
}

\section{Craig LaForce' \\ Gregory Feldman ${ }^{2}$ \\ Selwyn Spangenthal ${ }^{3}$ \\ Joerg $\mathrm{H}$ Eckert ${ }^{4}$ \\ Michelle Henley ${ }^{5}$ \\ Francesco Patalano ${ }^{4}$ \\ Peter D'Andrea ${ }^{5}$ \\ 'North Carolina Clinical Research, Raleigh, NC, USA; ${ }^{2}$ South Carolina Pharmaceutical Research, Spartanburg, SC, USA; ${ }^{3}$ American Health Research, Charlotte, NC, USA; ${ }^{4}$ Novartis Pharma AG, Basel, Switzerland; ${ }^{5}$ Novartis Pharmaceuticals Corporation, East Hanover, NJ, USA}

Correspondence: Craig LaForce North Carolina Clinical Research, 2615 Lake Dr, Raleigh, NC 27607, USA

Email claforce@nccr.com
Background: The purpose of this study was to confirm the efficacy and safety of twice-daily glycopyrrolate $15.6 \mu \mathrm{g}$, a long-acting muscarinic antagonist, in patients with stable, symptomatic, chronic obstructive pulmonary disease (COPD) with moderate-to-severe airflow limitation.

Methods: The GEM1 study was a 12-week, multicenter, double-blind, parallel-group, placebocontrolled study that randomized patients with stable, symptomatic COPD with moderate-tosevere airflow limitation to twice-daily glycopyrrolate $15.6 \mu \mathrm{g}$ or placebo $(1: 1)$ via the Neohaler ${ }^{\circledR}$ device. The primary objective was to demonstrate superiority of glycopyrrolate versus placebo in terms of forced expiratory volume in 1 second area under the curve between 0 and 12 hours post morning dose at week 12. Other outcomes included additional spirometric end points, transition dyspnea index, St George's Respiratory Questionnaire, COPD Assessment Test, rescue medication use, and symptoms reported by patients via electronic diary. Safety was also assessed during the study.

Results: Of the 441 patients randomized (glycopyrrolate, $n=222$; placebo, $n=219$ ), $96 \%$ of patients completed the planned treatment phase. Glycopyrrolate demonstrated statistically significant $(P<0.001)$ improvements in lung function versus placebo. Glycopyrrolate showed statistically significant improvement in the transition dyspnea index focal score, St George's Respiratory Questionnaire total score, COPD Assessment Test score, rescue medication use, and daily total symptom score versus placebo at week 12. Safety was comparable between the treatment groups. Conclusion: Significant improvement in lung function, dyspnea, COPD symptoms, health status, and rescue medication use suggests that glycopyrrolate is a safe and effective treatment option as maintenance bronchodilator in patients with stable, symptomatic COPD with moderate-to-severe airflow limitation.

Keywords: glycopyrronium, glycopyrrolate, lung function, chronic obstructive pulmonary disease, long-acting muscarinic antagonist, bronchodilator, twice daily

\section{Introduction}

Chronic obstructive pulmonary disease (COPD) is a major chronic respiratory disease that currently affects more than 400 million people and is one of the major causes of poor health and death worldwide. ${ }^{1}$ As per the survey conducted in 2010 , in the United States, COPD affects nearly 27 million individuals (14.8 million diagnosed and an estimated 12 million undiagnosed). The prevalence of COPD is lower among those aged $18-44$ years $(3.2 \%)$ than those aged $45-64$ years $(6.4 \%)$ and $\geq 65$ years $(9.8 \%){ }^{2}$ COPD is characterized by partially reversible airflow limitation, which is usually 
progressive and debilitating in nature. Airflow limitation in patients with COPD causes breathlessness, which ultimately affects the quality of life. ${ }^{3}$

The current GOLD (Global Initiative for Chronic Obstructive Lung Disease) strategy recommends focusing on improvement in health status, in addition to bronchodilation, as a therapeutic goal of symptomatic management in patients with COPD of different severities. ${ }^{4}$ Long-acting muscarinic antagonists (LAMAs) are well placed in the current GOLD strategy and recommended for the management of COPD, either alone or in combination with long-acting $\beta_{2}$-agonists (LABA) or inhaled corticosteroids (ICS) for patients at high risk of exacerbations. ${ }^{4}$

Glycopyrrolate, also known as glycopyrronium bromide, is an inhaled LAMA, developed for maintenance bronchodilator treatment to relieve symptoms in adult patients with COPD. ${ }^{5}$ The bronchodilatory effect of glycopyrrolate results from blockade of muscarinic $\mathrm{M}_{3}$ receptor, inhibiting parasympathetically mediated bronchoconstriction and indirectly inducing bronchodilation. Increase in the airway tone is exerted by activation of $\mathrm{M}_{3}$ muscarinic cholinergic receptors, whereas their blockade improves lung function, dyspnea, and health-related quality of life in patients with COPD. ${ }^{6}$

Glycopyrrolate $63 \mu \mathrm{g}$ (equivalent to glycopyrronium $50 \mu \mathrm{g})$ administered once daily in patients with moderateto-severe COPD provides significant improvement in lung function, breathlessness, health status, and reduction in rescue medication use versus placebo, with a comparable safety profile. $^{7}$ The efficacy and safety of glycopyrronium, once daily, has been shown to be comparable to tiotropium. ${ }^{8,9}$ It is approved for maintenance bronchodilator treatment in adult patients with COPD in more than 80 countries, including countries within the EU and Latin America, Japan, Canada, Switzerland, and Australia.

In the US, a separate Phase III clinical trial program was developed with glycopyrrolate $15.6 \mu \mathrm{g}$ administered twice daily. A dose-ranging study demonstrated that glycopyrrolate $15.6 \mu \mathrm{g}$ (equivalent to $12.5 \mu \mathrm{g}$ glycopyrronium), twice daily (bid), also resulted in statistically significant and clinically relevant improvements in trough forced expiratory volume in 1 second $\left(\mathrm{FEV}_{1}\right)$ versus placebo in patients with moderateto-severe COPD. ${ }^{10}$ In addition, the study also showed that for total daily doses in the range of 25-50 $\mu \mathrm{g}$, compared to once daily dosing, mean trough $\mathrm{FEV}_{1}$ dose-response curves favored the twice-daily regimen. On the basis of this data, the US Food and Drug Administration considered glycopyrrolate $15.6 \mu \mathrm{g}$ bid as a suitable dose to progress to Phase III studies in the US. This dosing regimen is now approved in the US for long-term maintenance treatment of airflow obstruction in COPD patients including chronic bronchitis and/or emphysema. ${ }^{11}$

Here, we report the results from the GEM1 (Glycopyrrolate Effect on syMptoms and lung function) clinical study, which evaluated the efficacy and safety of twice-daily glycopyrrolate $15.6 \mu \mathrm{g}$ in patients with stable, symptomatic COPD with moderate-to-severe airflow limitation.

\section{Methods \\ Trial registry}

Clinical trial number: NCT01709864.

\section{Study design}

This was a multicenter, double-blind, placebo-controlled, parallel-group, randomized study. Following the screening (between 1 and 7 days in length) and a 14-day run-in period, the eligible patients were randomized $(1: 1)$ to glycopyrrolate $15.6 \mu \mathrm{g}$ bid or placebo (both delivered via the Neohaler ${ }^{\circledR}$ [Novartis Pharmaceuticals, Basel, Switzerland] device) for 12 weeks (followed by study completion), and a 30-day follow-up period for evaluations (only for safety events; Figure 1). Randomization was stratified according to baseline smoking status. This study was conducted at 55 centers in the US. Additional details of the randomization and blinding procedures are included in Supplementary material 1. The first patient was enrolled in November 2012, and the last patient visit was completed in October 2013. Patients taking LABA/ ICS fixed-dose combination were switched to the nearest equivalent dose of ICS monotherapy at least 48 hours before the run-in period. ICS monotherapy at a stable dose regimen was permitted as COPD background therapy. Albuterol was used as rescue medication throughout the study. Written informed consent was obtained before enrollment to the study. The study protocol was approved by the Quorom Review, Inc Institutional Review Board for each study center and conducted according to the ethical principles of the Declaration of Helsinki and in compliance with Good Clinical Practice.

\section{Patients}

Men and women aged $\geq 40$ years with stable symptomatic COPD with airflow obstruction of levels 2 and 3 according to the GOLD 2011 strategy were included if they were either current or ex-smokers with a smoking history of at least 10 packyears and had postbronchodilator $\mathrm{FEV}_{1} \geq 30 \%$ and $<80 \%$ of the predicted normal, postbronchodilator $\mathrm{FEV}_{1} /$ forced vital capacity $(\mathrm{FVC}$ ) ratio $<0.70$, and modified Medical Research Council grade of at least 2 at run-in visit. 


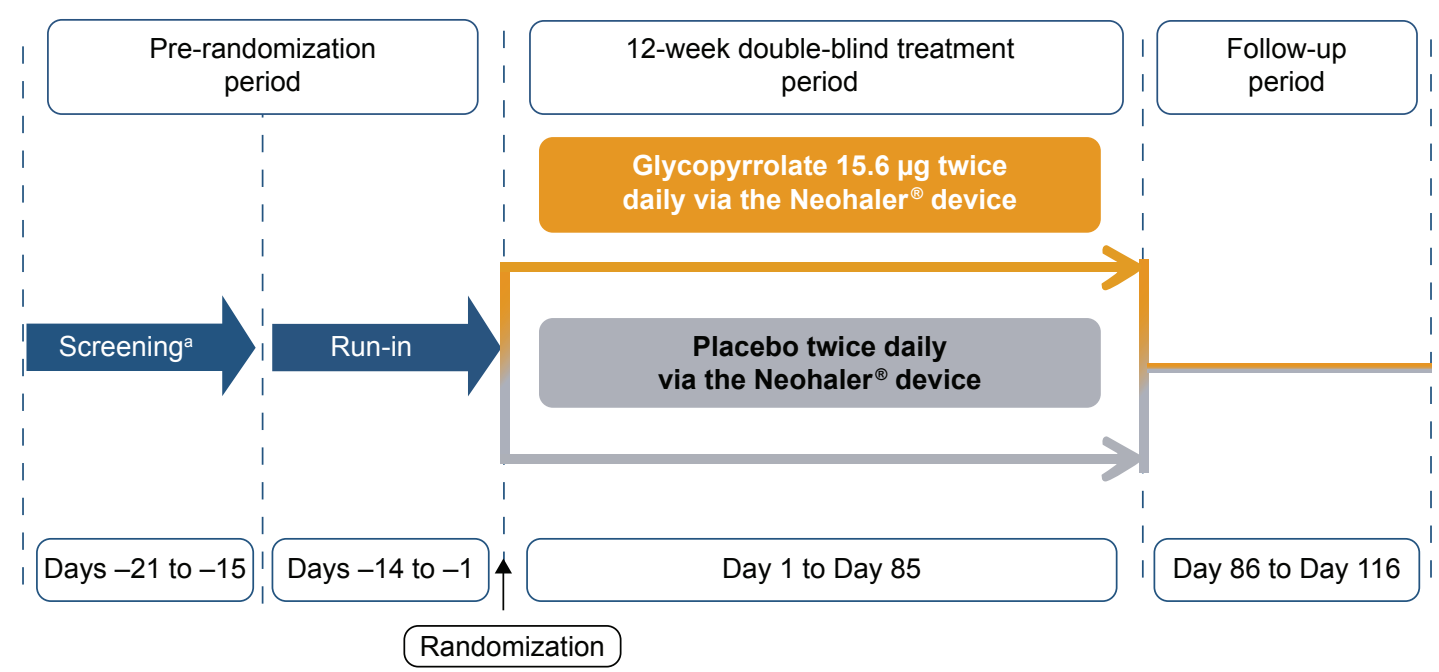

Figure I Study design.

Note: aFlexible between I and 7 days.

Patients were excluded if they had any history of asthma and/or COPD exacerbation that required treatment with antibiotics and/or systemic corticosteroids and/or hospitalization in the 6 weeks prior to screening or developed a COPD exacerbation between screening and first treatment. Patients with a history of long QT syndrome or prolonged QT at the run-in visit (QTcF $>450 \mathrm{~ms}$ ) were excluded. Detailed inclusion and exclusion criteria are provided in Supplementary material 2.

\section{Study objectives}

\section{Primary objective}

The primary objective of the study was to demonstrate the superiority of twice-daily glycopyrrolate $15.6 \mu \mathrm{g}$ versus placebo in standardized area under the curve (AUC) from 0 to 12 hours postdose for $\mathrm{FEV}_{1}\left(\mathrm{FEV}_{1} \mathrm{AUC}_{0-12 \mathrm{~h}}\right)$ at week 12.

\section{Secondary objectives}

A secondary objective of the study was to evaluate the improvement in trough $\mathrm{FEV}_{1}$ (mean of $\mathrm{FEV}_{1}$ measured between twenty three hours and fifteen minutes and, twenty three hours and forty five minutes post previous morning's dose) on day 2 and after 12 weeks' treatment with twicedaily glycopyrrolate $15.6 \mu \mathrm{g}$ versus placebo. Additional lung function efficacy objectives were to evaluate glycopyrrolate versus placebo in terms of $\mathrm{FEV}_{1} \mathrm{AUC}_{0-4 \mathrm{~h}}, \mathrm{FEV}_{1} \mathrm{AUC}_{4-8 \mathrm{~h}}$, $\mathrm{FEV}_{1} \mathrm{AUC}_{8-12 \mathrm{~h}}$, and peak $\mathrm{FEV}_{1}$ and $\mathrm{FVC}$ during 4 hours post morning dose on day 1 and week 12 , and $\mathrm{FEV}_{1}$ and FVC at each postbaseline time point. The time (minutes) to achieve $\geq 100 \mathrm{~mL}$ improvement in $\mathrm{FEV}_{1}$ from baseline on day 1 was also evaluated to determine the onset of action.
Additional efficacy objectives were to evaluate glycopyrrolate versus placebo in terms of improvement in health status assessed via the St George's Respiratory Questionnaire (SGRQ) total score at week 12; dyspnea assessed via the Transition Dyspnea Index (TDI) focal score at week 12; and reduction in rescue medication usage and COPD symptoms over 12 weeks' treatment using data collected twice daily via the electronic diary (e-diary). The percentage of patients achieving the minimal clinically important difference (MCID) in SGRQ total score and TDI focal score in the glycopyrrolate- and placebo-treated groups was also analyzed.

As an exploratory objective, improvement in health status with glycopyrrolate versus placebo was also evaluated using the COPD Assessment Test (CAT) at week 12.

The safety and tolerability of glycopyrrolate was evaluated by monitoring the adverse events (AEs) and serious AEs (SAEs), vital signs, electrocardiography, hematology, and blood chemistry assessments over the 12-week treatment period. All serious cardio- and cerebrovascular (CCV) events, atrial fibrillation, and atrial flutter, and all cases of death that occurred between randomization and the end of the follow-up period were evaluated by an independent adjudication committee. Serious CCV events were adjudicated by the major adverse cardiovascular events (MACE) outcome.

\section{Statistical analysis}

The full analysis set (FAS) included all randomized patients who received at least one dose of the study drug. The perprotocol set (PPS) included all patients in the FAS who did not have any major protocol deviations. The safety set 
included all patients who received at least one dose of the study drug. The FAS was used for the analysis of the primary objective and all other efficacy variables. The PPS was used for the supportive analysis of the primary variable. The safety set was used in the analysis of all safety variables.

$\mathrm{FEV}_{1} \mathrm{AUC}_{0-12 \mathrm{~h}}$ was calculated using the trapezoidal rule divided by length of time (12 hours). For the analysis of the primary efficacy end point $\left(\mathrm{FEV}_{1} \mathrm{AUC}_{0-12 \mathrm{~h}}\right)$, a mixed model for repeated measures was used. The model contained terms for treatment, baseline $\mathrm{FEV}_{1}$, baseline smoking status, baseline ICS use, visit, treatment $\times$ visit interaction, and baseline $\mathrm{FEV}_{1} \times$ visit interaction. An unstructured covariance matrix was assumed. Secondary end points were analyzed using the same mixed model as the primary end point, with the respective baseline values replacing baseline $\mathrm{FEV}_{1}$ as covariates as necessary. The proportion of patients who achieved the MCID in the SGRQ total score and TDI focal score was analyzed using a logistic regression model. Details on the sample size estimation are given in Supplementary material 3.

\section{Results}

Patients

A total of 441 patients were randomized (glycopyrrolate, $\mathrm{n}=222 ;$ placebo, $\mathrm{n}=219) ; 423(95.9 \%)$ patients completed the 12 weeks' planned treatment phase (glycopyrrolate, $n=215$ [96.8\%]; placebo, $\mathrm{n}=208$ [95.0\%]). Patients could continue to participate in the planned treatment phase even if they had permanently discontinued the study medication. The major reason for discontinuation from the planned treatment phase was patient/guardian decision $(2.5 \%)$. Two $(0.9 \%)$ patients in the placebo group discontinued the planned treatment phase due to an AE. Overall, 400 (90.7\%) patients completed the planned treatment phase without discontinuing the study treatment (glycopyrrolate, $n=206$ [92.8\%]; placebo, $n=194$ $[88.6 \%])$.

\section{Patient demographics and disease characteristics}

Demographic and baseline clinical characteristics were comparable between the treatment groups (Table 1). The majority

Table I Baseline demographics and disease characteristics (randomized set)

\begin{tabular}{|c|c|c|}
\hline Variable & Glycopyrrolate, $\mathbf{N}=\mathbf{2 2 2}$ & Placebo, $\mathbf{N}=219$ \\
\hline Age, years & $62.7(8.36)$ & $62.1(8.34)$ \\
\hline Men, n (\%) & $124(55.9)$ & $132(60.3)$ \\
\hline Caucasian, n (\%) & $205(92.3)$ & $193(88.1)$ \\
\hline \multicolumn{3}{|l|}{ Smoking status at baseline, $\mathrm{n}(\%)$} \\
\hline Ex-smoker & $85(38.3)$ & $87(39.7)$ \\
\hline Current smoker & $137(6 \mid .7)$ & $132(60.3)$ \\
\hline \multicolumn{3}{|l|}{ Severity of COPD, airflow limitation, $\mathrm{n}(\%)$} \\
\hline GOLD 2 & $138(62.2)$ & I44 (65.8) \\
\hline GOLD 3 & $83(37.4)$ & $73(33.3)$ \\
\hline \multicolumn{3}{|c|}{ Severity of COPD, ${ }^{a}$ combined assessment of COPD, $n(\%)$} \\
\hline GOLD B & $136(61.3)$ & $137(62.6)$ \\
\hline GOLD D & $85(38.3)$ & $80(36.5)$ \\
\hline Duration of COPD, years & $6.6(4.85)$ & $6.8(5.45)$ \\
\hline \multicolumn{3}{|c|}{ Number of COPD exacerbations in the previous year, $\mathrm{n}(\%)$} \\
\hline 0 & $174(78.4)$ & $165(75.3)$ \\
\hline I & $42(18.9)$ & $4 I(18.7)$ \\
\hline$\geq 2$ & $6(2.7)$ & $13(5.9)$ \\
\hline ICS use at baseline, $\mathrm{n}(\%)$ & $54(24.3)$ & $62(28.3)$ \\
\hline \multicolumn{3}{|l|}{ mMRC dyspnea scale, $\mathrm{n}(\%)$} \\
\hline Grade 2 & I2I (54.5) & $113(5 \mid .6)$ \\
\hline Grade 3 & $88(39.6)$ & $92(42.0)$ \\
\hline Grade 4 & $12(5.4)$ & $13(5.9)$ \\
\hline BDI focal score & $5.72(2.10)$ & $5.6(2.06)$ \\
\hline SGRQ total score & $52.4(17.20)$ & $54.1(16.84)$ \\
\hline CAT score & $20.4(8.07)$ & $20.7(7.54)$ \\
\hline Prebronchodilator $\mathrm{FEV}_{\mathrm{l}}, \mathrm{L}$ & $1.28(0.490)$ & $1.33(0.502)$ \\
\hline Postbronchodilator FEV & $1.52(0.540)$ & $1.58(0.54 \mathrm{I})$ \\
\hline Postbronchodilator $\mathrm{FEV}$, , \% predicted & $54.2(13.59)$ & $55.7(12.78)$ \\
\hline Postbronchodilator $\mathrm{FEV}$, reversibility, \% & $20.7(14.90)$ & $20.7(14.98)$ \\
\hline
\end{tabular}

Notes: ${ }^{a}$ GOLD 20I I; all data shown are presented as mean (standard deviation), unless specified; bassessed after administration of $84 \mu \mathrm{g}$ ipratropium bromide. Abbreviations: BDI, baseline dyspnea index; CAT, COPD assessment test; COPD, chronic obstructive pulmonary disease; FEV ${ }_{1}$, forced expiratory volume in I second; ICS, inhaled corticosteroid; mMRC, modified Medical Research Council; SGRQ, St George's Respiratory Questionnaire; GOLD, Global Initiative for Chronic Obstructive Lung Disease. 
of randomized patients were men $(58.0 \%)$ and Caucasians (90.2\%), with moderate airflow limitation (63.9\%). Most of the patients were in the GOLD 2011 Group B (61.9\%) and did not have COPD exacerbations in the previous year (76.9\%). The number of patients using an ICS at baseline as either a fixed-dose combination or monotherapy were comparable between the treatment groups (glycopyrrolate, $\mathrm{n}=54$ [24.3\%]; placebo, $\mathrm{n}=62$ [28.3\%]).

\section{Efficacy}

\section{Lung function}

The primary objective of the study was met. Glycopyrrolate was superior compared with placebo in terms of change from baseline in $\mathrm{FEV}_{1} \mathrm{AUC}_{0-12 \mathrm{~h}}$ at week 12 in the FAS (least squares mean [LSM] treatment difference $0.139 \mathrm{~L}$; $95 \%$ confidence interval [CI] 0.095, 0.184; $P<0.001$; Figure 2). The results of analysis of the primary end point in the PPS (LSM treatment difference $0.136 \mathrm{~L} ; 95 \%$ CI $0.092,0.181 ; P<0.001$ ) were consistent with the results seen in the FAS.

Glycopyrrolate demonstrated a statistically significant and clinically meaningful (MCID $\geq 100 \mathrm{~mL})^{12}$ improvement in $\mathrm{FEV}_{1} \mathrm{AUC}_{0-12 \mathrm{~h}}$ versus placebo on day 1 (LSM treatment difference $0.141 \mathrm{~L} ; 95 \%$ CI $0.114,0.169 ; P<0.001$ ). Improvement in $\mathrm{FEV}_{1} \mathrm{AUC}_{0-12 \mathrm{~h}}$ with glycopyrrolate versus placebo at week 12 in the subgroups based on age, sex, airflow limitation, baseline smoking status, and ICS use at baseline were generally consistent with the improvement seen in the overall study population (Figure 3 ). In patients with moderate COPD (GOLD 2), the improvement in lung

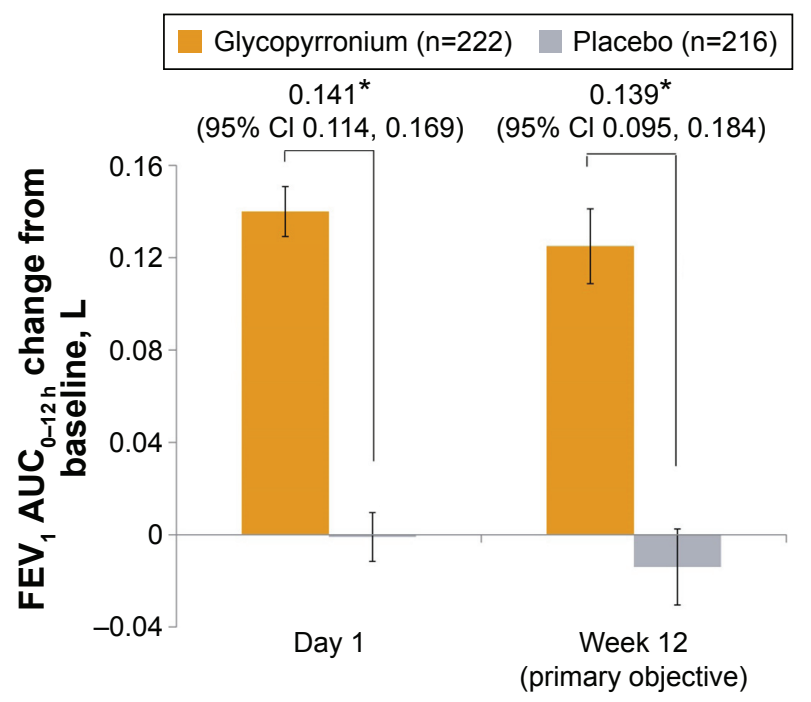

Figure 2 Improvement in $\mathrm{FEV}, \mathrm{AUC}_{0-12 \mathrm{~h}}$ on day I and at week 12 (FAS). Notes: Data are LSM (SE); $* P<0.00$ I.

Abbreviations: $\mathrm{Cl}$, confidence interval; FAS, full analysis set; LSM, least squares mean; $\mathrm{FEV}_{1}$, forced expiratory volume in I second; AUC, area under the curve; SE, standard error. function was more pronounced than in those with severe COPD (GOLD 3; Figure 3).

Superior bronchodilation with glycopyrrolate was supported by statistically significant and clinically meaningful improvement in trough $\mathrm{FEV}_{1}$ versus placebo at all assessed time points from day 2 (LSM treatment difference $0.115 \mathrm{~L}$; $P<0.001$ ) until week 12 (LSM treatment difference $0.115 \mathrm{~L}$; $P<0.001$; Figure 4).

Glycopyrrolate showed significant improvements in $\mathrm{FEV}_{1}$ at 5 and 15 minutes postdose compared with placebo on day 1 , demonstrating early onset of bronchodilation compared with placebo (all $P<0.001$; Figure 5A). Similar significant $(P<0.001)$ improvement in $\mathrm{FEV}_{1}$ with glycopyrrolate versus placebo was seen at all postbaseline time points assessed on day 1 and week 12 (Figures 5A and B). Improvements in $\mathrm{FEV}_{1}$ and $\mathrm{FVC}$ at all individual postbaseline time points during the 12 -week treatment period were significant with glycopyrrolate versus placebo (data not shown).

Glycopyrrolate also showed statistically significant improvement versus placebo for other lung function end points (Table S1). Improvement in $\mathrm{FEV}_{1} \mathrm{AUC}_{0-4 \mathrm{~h}}$, $\mathrm{FEV}_{1} \mathrm{AUC}_{4-8 \mathrm{~h}}$, and $\mathrm{FEV}_{1} \mathrm{AUC}_{8-12 \mathrm{~h}}$ with glycopyrrolate versus placebo was significant on day 1 and at week 12 (Table S1). The median time to onset of action (time to achieve $\geq 100 \mathrm{~mL}$ improvement in $\mathrm{FEV}_{1}$ from baseline on day 1) was 18.8 minutes for glycopyrrolate.

\section{Health status and dyspnea}

The improvement in the SGRQ total score from baseline at week 12 with glycopyrrolate was statistically significant versus placebo (LSM treatment difference -2.8 units; 95\% CI -5.0, -0.5; $P=0.016$; Figure 6). The percentage of patients who achieved a clinically important improvement in SGRQ total score $(\geq 4$ units reduction) was higher with glycopyrrolate (49.0\%) compared with placebo $(40.6 \%$; odds ratio $1.43 ; 95 \%$ CI 0.95, 2.15 ; $P=0.083$; Figure 6). A statistically significant decrease in CAT score from baseline was observed with glycopyrrolate compared with placebo at week 12 (LSM treatment difference -1.2 points; 95\% CI -2.3, $-0.1 ; P=0.040$ ) (Table S1).

A statistically significant improvement in dyspnea from baseline, as measured by the TDI focal score, was observed at week 12 with glycopyrrolate versus placebo (LSM treatment difference 0.92 points; $95 \%$ CI $0.32,1.53 ; P=0.003$; Figure 7 ). A significantly higher proportion of patients treated with glycopyrrolate achieved the clinically important improvement in TDI focal score at week 12 versus placebo $(60.5 \%$ versus $41.5 \%$; odds ratio 2.27; 95\% CI 1.49, 3.47; $P<0.001$; Figure 7). 
Subgroups

Age (years): $<65$

Age (years): $\geq 65$

Sex: male

Sex: female

Smoking history: ex-smoker

Smoking history: current smoker

Airflow limitation: GOLD 2

Airflow limitation: GOLD 3

Baseline ICS use: yes

Baseline ICS use: no

Overall

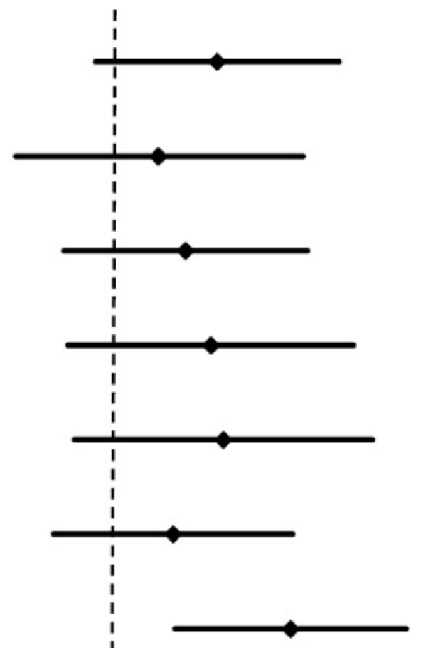

LSM $(95 \% \mathrm{Cl})$

N1/N2

$0.151(0.093,0.209)$

$129 / 125$

$0.123(0.055,0.192)$

93/91

$0.136(0.078,0.194)$

$124 / 129$

$0.148(0.080,0.216)$

$98 / 87$

$0.154(0.083,0.225)$

$85 / 86$

$0.130(0.073,0.187)$

$137 / 130$

$0.186(0.131,0.241)$

$138 / 142$

$0.057(-0.017,0.131)$

$0.143(0.056,0.230)$

$54 / 61$

$0.137(0.086,0.189)$

$168 / 155$

$83 / 73$

\section{$222 / 216$}

$0.139(0.095,0.184)$

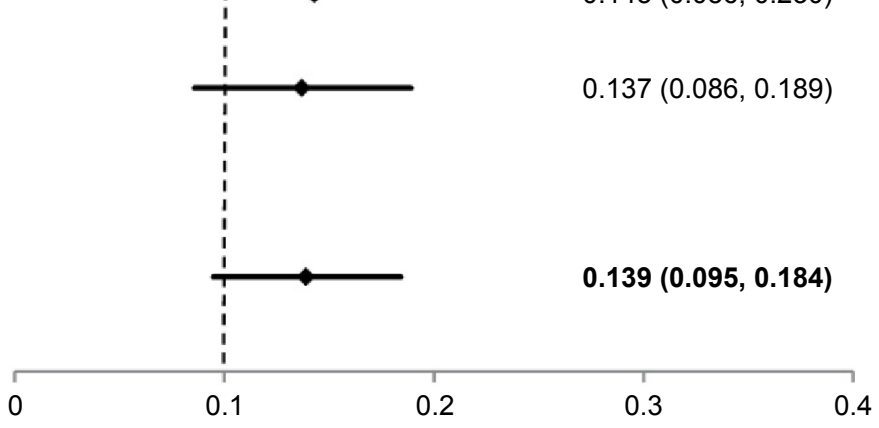

LSM $(95 \% \mathrm{CI})$ treatment difference (L)

Figure 3 Forest plot of the treatment differences between glycopyrrolate and placebo in $\mathrm{FEV}_{1} \mathrm{AUC}_{0-12 \mathrm{~h}}$ by subgroups at week 12.

Notes: All $P$-values are $\leq 0.001$ except GOLD 3 subgroup; $\mathrm{NI}=$ number of patients analyzed in the glycopyrrolate group; $\mathrm{N} 2=$ number of patients analyzed in the placebo group.

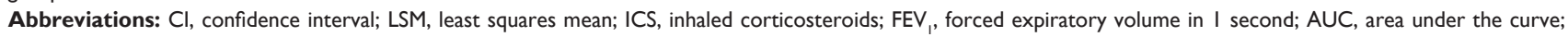
GOLD, Global Initiative for Chronic Obstructive Lung Disease.

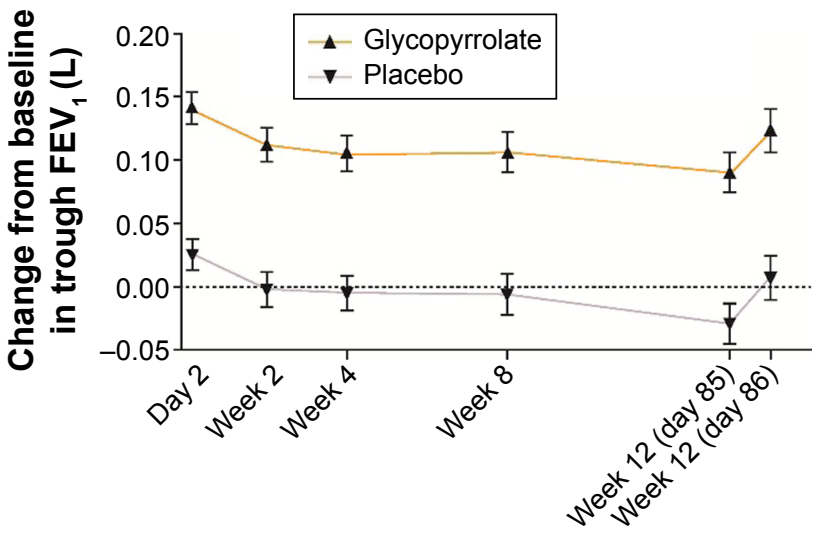

Figure 4 Improvement in trough $\mathrm{FEV}_{\text {, }}$ (FAS).

Notes: Data are LSM (SE); differences between glycopyrrolate and placebo were significant $(P<0.00 \mathrm{I})$ at each visit during the treatment period; glycopyrrolate $(n=2|7-2| 8)$ and placebo $(n=208-2 \mid 4)$.

Abbreviations: $\mathrm{FEV}$, forced expiratory volume in I second; FAS, full analysis set; LSM, least squares mean; SE, standard error.

\section{Rescue medication use and symptom score/end points}

Treatment with glycopyrrolate resulted in a significant decrease from baseline in rescue medication use over the 12-week treatment period compared with placebo. A statistically significant decrease in daily (LSM treatment difference $-0.76 \mathrm{puffs} /$ day; $P<0.001$ ), daytime (LSM treatment difference -0.45 puffs/day; $P<0.001$ ), and nighttime (LSM treatment difference -0.35 puffs/night; $P=0.002$ ) number of puffs and significant increase in the percentage of days with no rescue medication use (LSM treatment difference $6.1 ; P<0.027)$ was observed for glycopyrrolate compared with placebo (Table S2). In addition, glycopyrrolate also showed significant improvement in daily total symptom score and daytime total symptom score compared with placebo 
A

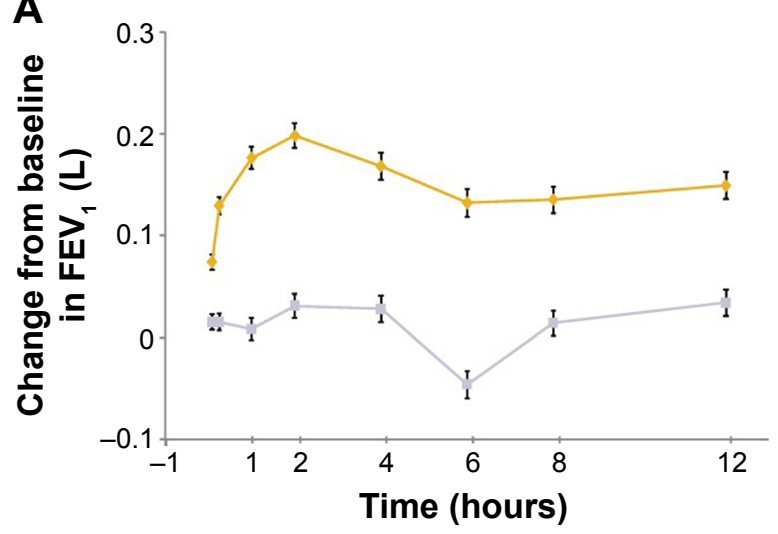

B

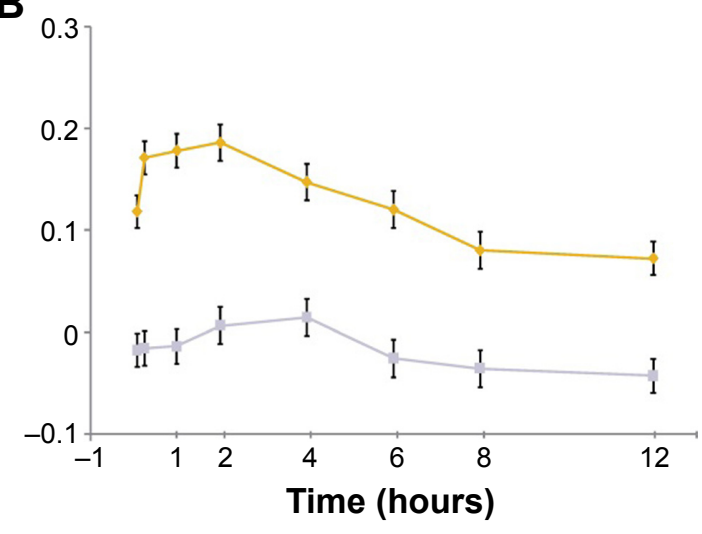

$\leftarrow$ Glycopyrrolate $=$ Placebo

Figure 5 Serial measurements of FEV, by timepoint on (A) day I and (B) week 12 (FAS).

Notes: Data are LSM (SE); treatment differences: $P<0.00$ I for glycopyrrolate versus placebo at each assessed timepoint.

Abbreviations: $\mathrm{FEV}_{\text {, }}$, forced expiratory volume in I second; FAS, full analysis set; LSM, least squares mean; SE, standard error.

(Table S2). The percentage of days the patient was able to perform usual daily activities was significantly increased with glycopyrrolate compared with placebo.

\section{Safety}

The number of patients who experienced at least one $\mathrm{AE}$ during the treatment period was comparable between the treatment groups (glycopyrrolate, $\mathrm{n}=95[42.8 \%]$; placebo, $\mathrm{n}=89$ [41.2\%]; Table 2). COPD (including exacerbation) was the most commonly reported $\mathrm{AE}$, whose incidence was comparable between the treatment groups (glycopyrrolate $10.4 \%$ versus placebo $13.4 \%$ ). The maximum severity of the majority of AEs reported during the treatment period was mild or moderate in both the treatment groups. The proportion of patients who reported severe AEs was lower with glycopyrrolate compared with placebo (glycopyrrolate $3.6 \%$; placebo 5.6\%). The incidence of SAEs during the treatment period was similar in both treatment groups (glycopyrrolate $5.0 \%$; placebo $5.6 \%$ ). There were no deaths in the glycopyrrolate group. One patient died in the placebo group due to congestive heart failure. The proportion of patients who discontinued study treatment due to AEs (glycopyrrolate 2.7\% versus placebo $3.7 \%$ ), SAEs (glycopyrrolate $1.4 \%$ versus placebo $2.3 \%$ ), and non-SAEs (glycopyrrolate $1.4 \%$ versus placebo $1.4 \%$ ) was generally similar between the treatment groups. The percentage of patients with adjudicated serious CCV AEs with glycopyrrolate and placebo was 2.3\% (five patients) and 2.8\% (six patients), respectively. Adjudicated MACE were reported at a higher rate with placebo $(2.3 \%)$ compared with glycopyrrolate $(0.9 \%$; Table 3$)$. Atrial
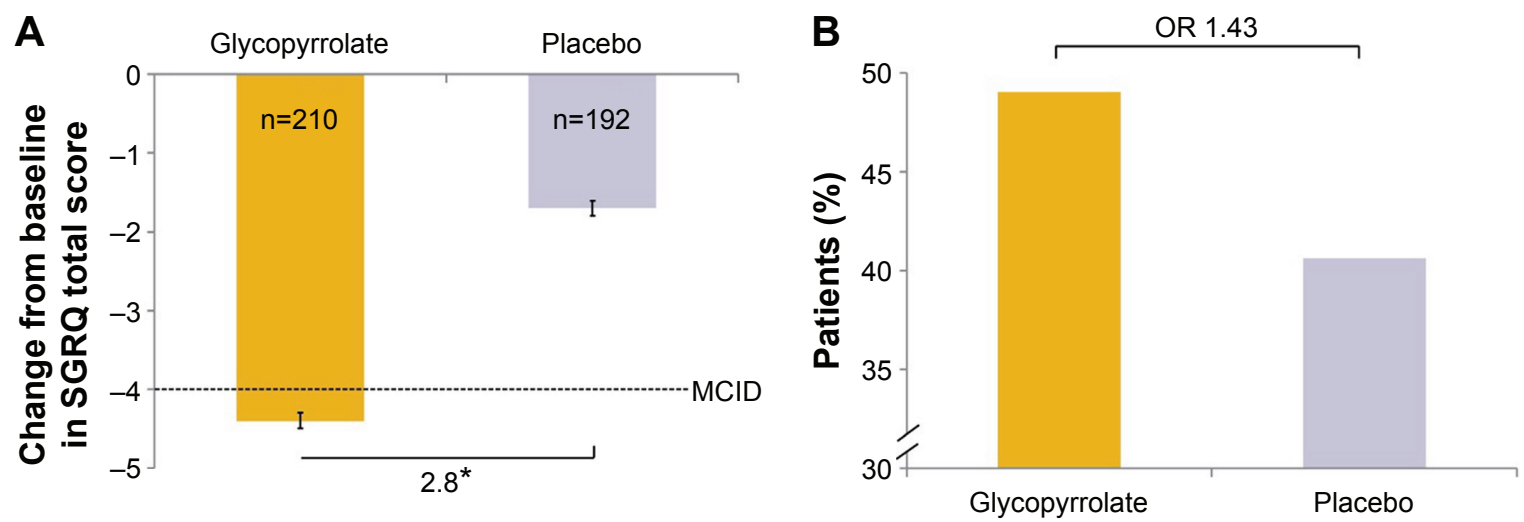

Figure 6 SGRQ total score at week 12 in FAS (A) change from baseline in each treatment group and (B) percentages of patients achieving the MCID ( $\geq 4$ units reduction) in SGRQ total score.

Notes: $* P<0.05$. Data are LSM (SE) in (A).

Abbreviations: FAS, full analysis set; LSM, least squares mean; MCID, minimal clinically important difference; OR, odds ratio; SE, standard error; SGRQ, St George's Respiratory Questionnaire. 

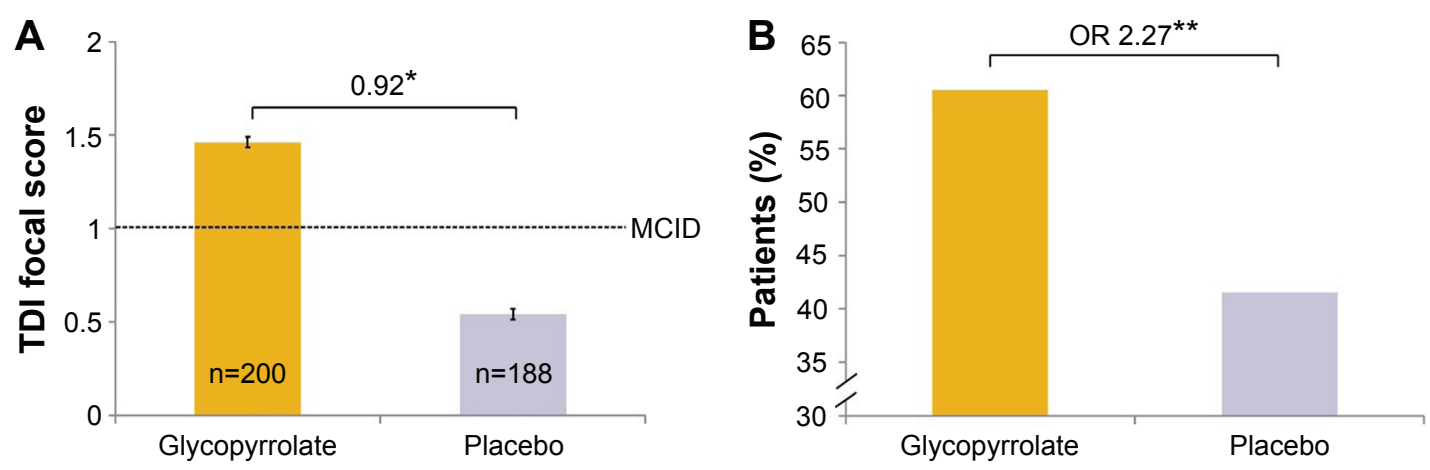

Figure 7 Improvement in TDI focal score in FAS (A) TDI focal score after 12 weeks and (B) percentages of patients achieving the MCID ( $\geq I$ unit). Notes: $* P<0.01$, $* * P<0.001$. Data are LSM (SE) in (A).

Abbreviations: FAS, full analysis set; LSM, least squares mean; MCID, minimal clinically important difference; OR, odds ratio; SE, standard error; TDI, transition dyspnea index.

Table 2 AEs and SAEs ( $\geq 1 \%$ of patients in either treatment group), and death (safety set)

\begin{tabular}{|c|c|c|}
\hline Preferred term & Glycopyrrolate, $\mathbf{N}=\mathbf{2 2 2}$, n (\%) & Placebo, $N=216, n$ (\%) \\
\hline Patients with at least one $A E$ & $95(42.8)$ & $89(41.2)$ \\
\hline $\mathrm{COPD}^{\mathrm{a}}$ & $23(10.4)$ & $29(13.4)$ \\
\hline Headache & $8(3.6)$ & $6(2.8)$ \\
\hline Upper respiratory tract infection & $8(3.6)$ & $6(2.8)$ \\
\hline Cough & $7(3.2)$ & $5(2.3)$ \\
\hline Nasal congestion & $4(1.8)$ & $4(1.9)$ \\
\hline Oropharyngeal pain & $4(1.8)$ & $4(1.9)$ \\
\hline Pneumonia & $4(1.8)$ & 0 \\
\hline Bronchitis & $3(1.4)$ & $2(0.9)$ \\
\hline Lower respiratory tract infection & $3(1.4)$ & 0 \\
\hline Nasopharyngitis & $3(1.4)$ & $7(3.2)$ \\
\hline Sinusitis & $3(1.4)$ & $2(0.9)$ \\
\hline Urinary tract infection & $3(1.4)$ & $3(1.4)$ \\
\hline Vertigo & $3(1.4)$ & 0 \\
\hline Upper respiratory tract infection bacterial & $2(0.9)$ & $5(2.3)$ \\
\hline Upper respiratory tract infection viral & $2(0.9)$ & $3(1.4)$ \\
\hline Hyperkalemia & $\mathrm{I}(0.5)$ & $3(1.4)$ \\
\hline Abdominal pain & 0 & $3(1.4)$ \\
\hline Acute respiratory failure & 0 & $3(1.4)$ \\
\hline Patients with at least one SAE & II (5.0) & $12(5.6)$ \\
\hline COPDa $^{a}$ & $2(0.9)$ & $3(1.4)$ \\
\hline Death & 0 & $\mathrm{I}(0.5)$ \\
\hline
\end{tabular}

Note: ${ }^{a}$ Worsening of COPD which includes COPD exacerbation.

Abbreviations: AE, adverse event; COPD, chronic obstructive pulmonary disease; SAE, serious adverse event.

Table 3 Adjudicated serious CCV AEs during the study (safety set)

\begin{tabular}{|c|c|c|}
\hline Adjudicated event & Glycopyrrolate $\mathbf{N}=\mathbf{2 2 2}$, n (\%) & Placebo $\mathbf{N}=216, \mathrm{n}(\%)$ \\
\hline Patients with at least one serious CCV AE & $5(2.3)$ & $6(2.8)$ \\
\hline MACE & $2(0.9)$ & $5(2.3)$ \\
\hline Nonfatal myocardial infarction & $2(0.9)$ & $\mathrm{I}(0.5)$ \\
\hline Coronary revascularization (CABG or $\mathrm{PCl}$ ) & 0 & $3(1.4)$ \\
\hline Heart failure requiring hospitalization & 0 & $\mathrm{I}(0.5)$ \\
\hline Nonfatal stroke & 0 & $\mathrm{I}(0.5)$ \\
\hline Non-MACE serious CCV AE & $3(1.4)$ & $4(1.9)$ \\
\hline
\end{tabular}

Abbreviations: AE, adverse event; $C A B G$, coronary artery bypass grafting; $C C V$, cerebro- and cardiovascular; $M A C E$, major adverse cardiovascular events; PCI, percutaneous coronary intervention. 
fibrillation/flutter was reported in six patients $(2.7 \%)$ in the glycopyrrolate group and three patients $(1.4 \%)$ in the placebo group. Of these, new-onset atrial fibrillation/flutter occurred in two patients $(0.9 \%)$ treated with glycopyrrolate and one patient $(0.5 \%)$ treated with placebo. The proportion of patients with newly occurring or worsening clinically notable QTcF (Fridericia's corrected QT interval) values was similar between the treatment groups. One patient from each treatment group had QTcF values $>480 \mathrm{~ms}$. Laboratory parameters and clinically notable vital sign findings were generally similar between the treatment groups.

\section{Discussion}

LAMAs either alone or in combination with LABA are now recommended as first choice for maintenance treatment of COPD. In this GEM1 clinical study in patients with moderateto-severe COPD, glycopyrrolate, a LAMA, monotherapy showed significant improvements in lung function, dyspnea, and health status over 12 weeks' treatment versus placebo. The primary end point of superiority in terms of improvement in $\mathrm{FEV}_{1} \mathrm{AUC}_{0-12 \mathrm{~h}}$ with glycopyrrolate versus placebo at week 12 was met. Glycopyrrolate $15.6 \mu \mathrm{g}$ bid showed a superior and clinically meaningful improvement in $\mathrm{FEV}_{1} \mathrm{AUC}_{0-12 \mathrm{~h}}$ at both day 1 and week 12, which supports its therapeutic efficacy in patients with COPD. This therapeutic efficacy is further supported by statistically and clinically significant improvements in all the lung function parameters assessed on day 1 and at week 12 versus placebo. The improvement in lung function in this study is in concordance with earlier GLOW $1^{7}$ and GLOW $2^{9}$ studies where glycopyrronium $50 \mu \mathrm{g}$ once daily showed an improvement of 108 and $97 \mathrm{~mL}$ in trough $\mathrm{FEV}_{1}$, respectively, at week 12 compared to 115 $\mathrm{mL}$ seen in this study. Glycopyrrolate $15.6 \mu \mathrm{g}$ bid dose was selected for this study based on the findings of a dose-ranging study in which glycopyrrolate $15.6 \mu \mathrm{g}$ bid showed statistically significant and clinically meaningful improvement in trough $\mathrm{FEV}_{1}$ versus placebo in patients with $\mathrm{COPD}^{10}$ and was considered a reasonable dose for a twice-daily regimen following regulatory interactions for advancement to Phase III to support registration in the United States.

The goal of COPD management is to improve a patient's functional status and quality of life by maintaining the optimal lung function, improving symptoms and health status. ${ }^{4}$ Glycopyrronium $50 \mu \mathrm{g}$ once daily has been shown to improve lung function in moderate-to-very-severe COPD patients who were predominantly Caucasians ${ }^{7,9}$ and also in a Chinese population. ${ }^{13}$ The overall results of this study are also in agreement with the earlier studies in terms of efficacy and safety parameters. Onset of action is an important criterion for choosing bronchodilators for patients requiring rapid bronchodilation, preferably in the morning. Patients with COPD struggle with the morning symptoms, particularly dyspnea and activity limitation. ${ }^{14}$ The onset of action of glycopyrrolate observed in this study (18.8 minutes on day 1 ) was comparable with that observed in other studies. ${ }^{7}$ Rapid-acting bronchodilators could be more effective than the relatively slow-onset bronchodilators in providing rapid relief of symptoms after morning dosing. ${ }^{15}$ In addition, prompt symptom relief could be a key factor in patient compliance; medication that does not have an immediate effect on symptoms might reduce the chance of a patient continuing with treatment. ${ }^{16}$ Hence, symptomatic patients could benefit more from glycopyrrolate therapy.

The current GOLD strategy classifies severity of COPD based on airflow limitation, symptoms, and rate of exacerbations. ${ }^{4}$ In this study, patients with moderateto-severe airflow limitation (GOLD 2 and GOLD 3) were included. As per the current GOLD strategy, patients of both GOLD B (61.9\%) and GOLD D (37.4\%) groups were enrolled in this study. Glycopyrrolate showed improvement in lung function irrespective of disease severity. However, in patients with moderate COPD (GOLD 2), the improvement in lung function was more pronounced than in those with severe COPD (GOLD 3). Small sample size in GOLD 3 group limits interpretation of these findings. COPD is a progressive disease, and lung function deteriorates rapidly in patients with moderate COPD, if not treated. ${ }^{17}$ Prior to enrollment in this study, approximately $80 \%$ of all patients took COPDrelated medications. Early treatment with a rapid-acting and sustained-duration long-acting bronchodilator such as glycopyrrolate can maintain optimal lung function.

Improvement in symptoms, in addition to bronchodilation, is also an important goal for effective management of COPD. In this study, glycopyrrolate significantly improved the SGRQ total score and the TDI focal score at week 12. Although there was $\geq 4$ unit improvement from baseline in the SGRQ total score ( -4.4 units) and $\geq 1$ unit improvement in the TDI focal score (1.46 units) in patients treated with glycopyrrolate, the treatment differences versus placebo did not reach the MCID. This might be due to improvement in change from baseline in SGRQ total score (-1.7 units) and in TDI focal score (0.54 units) in placebo-treated patients. Similar unexpected improvement in the health status scores in placebo-treated patients was observed in another clinical trial conducted with a LAMA. ${ }^{18}$ This may be, in part, due to closer patient follow-up and monitoring during clinical study participation. 
The proportion of patients who achieved the MCID in SGRQ total score and TDI focal score was higher with glycopyrrolate versus placebo in this study. Furthermore, (CAT, which was an exploratory objective in the study to evaluate the improvement in health status), glycopyrrolate showed significant improvement in the CAT score compared with placebo at week 12 . The daily total symptom score was significantly improved, and rescue medication use was significantly reduced compared to baseline with glycopyrrolate versus placebo. Improvement in the symptom score with glycopyrrolate translated into an increase in the number of symptom free days for the patients where they were able to perform usual daily activities. These results support the therapeutic benefit of glycopyrrolate in improving health status and quality of life in patients with COPD.

In this study, the safety profile of glycopyrrolate was comparable to that of placebo. One death was reported during the study in the placebo group due to congestive heart failure. AEs were comparable between the groups, with COPD (including exacerbation) being the most frequently reported AE. The safety profile of glycopyrrolate was similar to that observed in other studies. ${ }^{7,8}$ There were no new or unexpected safety findings in this study. Incidence of anticholinergic AEs such as dry mouth, blurred vision, and urinary tract infections were comparable between the groups in this study. There was no imbalance in MACE between the treatment groups based on the adjudication of serious CCV AEs. Overall, the results of this study support the efficacy and safety of glycopyrrolate $15.6 \mu \mathrm{g}$ bid as an additional dosage regimen for glycopyrrolate in patients with moderate-to-severe COPD.

Some of the study limitations are the duration of study (12 weeks) and sample size, which limit the power to perform analysis on some endpoints such as exacerbations and patient-reported outcomes. Another limitation was that no active comparator was included in this study. Hence, longterm studies and studies with active comparators would be needed to assess the long-term safety of glycopyrrolate $15.6 \mu \mathrm{g}$ twice daily and to assess its safety and efficacy compared to other LAMAs.

\section{Conclusion}

The early onset of bronchodilation and the sustained bronchodilatory effect of glycopyrrolate demonstrated in this study provides evidence of its therapeutic efficacy, with a safety profile comparable to placebo. The efficacy and safety profile of glycopyrrolate $15.6 \mu \mathrm{g}$ twice daily are generally similar with that observed with glycopyrronium $50 \mu \mathrm{g}$ once daily in patients with moderate-to-severe COPD. Improvement in symptoms and health status with glycopyrrolate is consistent with the current GOLD focus in terms of management of patients with COPD.

\section{Acknowledgments}

This study was sponsored by Novartis Pharma AG. The authors thank the patients who participated and the staff at the participating clinical centers. The authors also thank Novartis clinical team members Fernando Mota, Pamalar Lewis, Cathy Surdouski, Colleen Spotts, Michael Kleinhoffer, and Janet Jenkins for their contributions in executing the study and Santanu Sannigrahi (professional medical writer; Novartis) for assistance in the preparation of this manuscript. All authors participated in the development and writing of the manuscript and take full responsibility for the content of the article. The study was funded by Novartis Pharma AG.

\section{Disclosure}

Prof LaForce has received consultancy fees from Novartis. Prof Spangenthal has received honoraria from AstraZeneca, Forest, Mylan Labs, Novartis, and GlaxoSmithKline. Joerg H Eckert, Michelle Henley, Francesco Patalano, and Peter D'Andrea are employees of the study sponsor, Novartis. The authors report no other conflicts of interest in this work.

\section{References}

1. Ferkol T, Schraufnagel D. The global burden of respiratory disease. Ann Am Thorac Soc. 2014;11(3):404-406.

2. National Heart, Lung and Blood Institute. Morbidity and Mortality: 2012 Chart Book on Cardiovascular, Lung, and Blood Diseases. 2012. Available from: http://www.nhlbi.nih.gov/research/reports/2012-mortalitychart-book. Accessed 22 July, 2015.

3. Ries AL. Impact of chronic obstructive pulmonary disease on quality of life: the role of dyspnea. Am J Med. 2006;119(10 Suppl 1):12-20.

4. Global Strategy for the Diagnosis, Management and Prevention of COPD, Global Initiative for Chronic Obstructive Lung Disease. 2016. Available from: http://www.goldcopd.org. Accessed February 2, 2016.

5. Seebri Breezhaler ${ }^{\circledR}$ (glycopyrronium bromide) [summary of product characteristics]. Nuremberg, Germany: Novartis Pharma GmbH; 2013. Available from: http://www.ema.europa.eu/docs/en_GB/document_ library/EPAR_-_Product_Information/human/002430/WC500133769. pdf. Accessed February 2, 2016.

6. Domingo C. Ultra-LAMA, ultra-LABA, ultra-inhaled steroids? The future has landed. Arch Bronconeumol. 2013;49(4):131-134.

7. D’Urzo A, Kerwin E, Overend T, D’Andrea P, Chen H, Goyal P. Once daily glycopyrronium for the treatment of COPD: pooled analysis of the GLOW1 and GLOW2 studies. Curr Med Res Opin. 2014;30(3): 493-508.

8. Chapman KR, Beeh KM, Beier J, et al. A blinded evaluation of the efficacy and safety of glycopyrronium, a once-daily long-acting muscarinic antagonist, versus tiotropium, in patients with COPD: the GLOW5 study. BMC Pulm Med. 2014;14:4.

9. Kerwin E, Hebert J, Gallagher N, et al. Efficacy and safety of NVA237 versus placebo and tiotropium in patients with COPD: the GLOW2 study. Eur Respir J. 2012;40(5):1106-1114. 
10. Arievich H, Overend T, Renard D, et al. A novel model-based approach for dose determination of glycopyrronium bromide in COPD. BMC Pulm Med. 2012;12:74.

11. FDA approves new Novartis dual combination bronchodilator Utibron ${ }^{\mathrm{TM}}$ Neohaler ${ }^{\circledR}$ for patients with chronic obstructive pulmonary disease, October 29, 2015. Available from: http://www.pharma.us.novartis. com/info/newsroom/news-description.jsp?id=137236. Accessed May 2, 2016.

12. Jones PW, Beeh KM, Chapman KR, Decramer M, Mahler DA, Wedzicha JA. Minimal clinically important differences in pharmacological trials. Am J Respir Crit Care Med. 2014;189(3):250-255.

13. Wang C, Sun T, Huang Y, et al. Efficacy and safety of once-daily glycopyrronium in predominantly Chinese patients with moderateto-severe chronic obstructive pulmonary disease: the GLOW7 study. Int J Chron Obstruct Pulmon Dis. 2015;10:57-68.
14. Kessler R, Partridge MR, Miravitlles M, et al. Symptom variability in patients with severe COPD: a pan-European cross-sectional study. Eur Respir J. 2011;37(2):264-272.

15. Roche N, Chavannes NH, Miravitlles M. COPD symptoms in the morning: impact, evaluation and management. Respir Res. 2013;14:112.

16. Bourbeau J, Bartlett SJ. Patient adherence in COPD. Thorax. 2008;63(9): 831-838.

17. Decramer M, Cooper CB. Treatment of COPD: the sooner the better? Thorax. 2010;65(9):837-841.

18. Rennard SI, Scanlon PD, Ferguson GT, et al. ACCORD COPD II: a randomized clinical trial to evaluate the 12-week efficacy and safety of twice-daily aclidinium bromide in chronic obstructive pulmonary disease patients. Clin Drug Investig. 2013;33(12):893-904.

\section{Publish your work in this journal}

The International Journal of COPD is an international, peer-reviewed journal of therapeutics and pharmacology focusing on concise rapid reporting of clinical studies and reviews in COPD. Special focus is given to the pathophysiological processes underlying the disease, intervention programs, patient focused education, and self management protocols.

\section{Dovepress}

This journal is indexed on PubMed Central, MedLine and CAS. The manuscript management system is completely online and includes a very quick and fair peer-review system, which is all easy to use. Visit http://www.dovepress.com/testimonials.php to read real quotes from published authors.

Submit your manuscript here: http://www.dovepress.com/international-journal-of-chronic-obstructive-pulmonary-disease-journal 